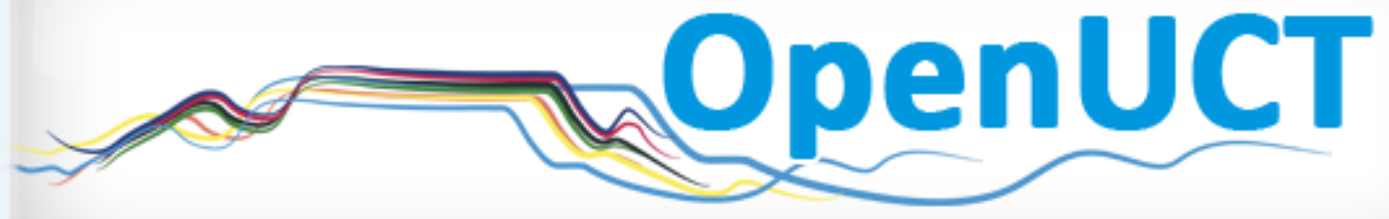

This is the author-approved manuscript version of a journal article published in:

Luckett, K. 2007. The introduction of external quality assurance in South African higher education: an analysis of stakeholder response. Quality in Higher Education. 13(2): 97-116. DOI: 10.1080/13538320701629129.

It is made available under the terms of agreement between the author and the journal, and in accordance with the University of Cape Town's Open Access Policy for the purposes of research, teaching and private study.

http://www.openuct.uct.ac.za/sites/default/files/UCTOpenAccessPolicy.pdf 


\title{
The Introduction of External Quality Assurance in South African Higher Education: An Analysis of Stakeholder Response
}

\author{
Kathy Luckett \\ Centre for Higher Education Development, University of Cape Town, South Africa. \\ Email:kathy.luckett@uct.ac.za
}

\begin{abstract}
This paper analyses the take-up of proposals for a national quality assurance system in South Africa using different approaches to quality assurance to classify stakeholder responses to survey and interview questions. The context of the study was the introduction of an external quality assurance system for South African higher education by an agency of the Department of Education, the Higher Education Quality Committee (HEQC) in 2004. A conceptual framework using Habermas's distinctions between system and strategic action on the one hand and lifeworld and communicative action on the other was set up to map different approaches to quality assurance and to analyse the data. Stakeholder opinion on the HEQC's proposals for institutional audit and programme accreditation was gathered using survey questionnaire and depth-interview instruments. Given that quality assurance in South Africa has been conceived as a means of furthering the state's 'transformation agenda' for higher education, different and sometimes conflicting approaches to quality assurance exist in the higher education community—underpinned by different values, discourses and purposes for higher education. The study shows that these differences of opinion were shaped more strongly by the respondents' position in the social structure (apartheid defined class and race position) than by their social role (academic, manager, quality assurance manager) in the policy-making process. The paper concludes by suggesting that this finding may be explained if one understands the adoption and intended implementation of quality assurance policy to be a lifeworld matter. The contribution of Habermas' notions of lifeworld and system to conceptualising and understanding quality assurance systems is put forward.
\end{abstract}

Keywords: Quality assurance; higher education; South Africa; policy analysis; policy adoption

\section{Setting the policy agenda}

To understand the intended role of the external quality assurance of higher education in South Africa, it is important to briefly review how the policy agenda for higher education 
was set in the post-apartheid period: what 'problems' were discursively constructed by the new state and why quality assurance by an external state agency was proposed as one of the 'solutions' to these 'problems'. Early policy framing documents (DoE, 1977, 2001) identified the following problems in higher education and placed them on the policy agenda: historical inequality leading to unequal standards of provision, irrelevance of the curriculum to the development needs of the economy, lack of access and representivity (representation according to race group demographics) in student and staff compositions, inefficiency and ineffectiveness (manifested particularly in high failure and drop-out rates, especially for black students), and poor management (especially in the historically disadvantaged institutions). In the policy discourse, the cause of these problems is unsurprisingly located in the previous unjust and dysfunctional apartheid education system. Just as the old state is blamed for the 'problems' identified in the system, so the new state is set up to 'solve' them. The discourse about the dire need for state-driven transformation of higher education both enabled and constrained what 'solutions' and courses of action could be proposed to 'solve' the 'problems' identified. The exercise of state power was seen as the key means of transforming the system and so state agencies were established and heavy state steering and intervention were justified. Thus, in South Africa, external quality assurance has been proposed as one mechanism of the state for achieving greater efficiency, effectiveness, equity and responsiveness in the higher education system (the 'transformation agenda'). In particular, quality assurance is seen as a means of ensuring high quality teaching and learning opportunities for all students, that is, contributing to the state's provision of equal educational opportunities for all. The other mechanisms proposed for achieving greater efficiency, effectiveness, equity and responsiveness are state control of planning and funding, and more recently a more drastic policy of institutional mergers, involving the merging of selected historically disadvantaged institutions with selected historically advantaged institutions. This paper focuses on the quality process.

The HEQC was mooted in the Education White Paper 3 (1997), legislated through the Higher Education Act of 1997 and established in May 2001 as a permanent committee of the Council on Higher Education (CHE, an independent statutory body established by the same legislation), with a mandate to promote quality in higher education; audit the quality assurance mechanisms of higher education institutions; and accredit programmes of higher education. The HEQC is thus authorised by law to exercise bureaucratic power and it is expected to promote the Department of Education's transformation agenda. In policy discourse, the 'problem' and its 'solution' are often rolled into one (Taylor et al., 1997). In the South African case, acceptance of the 'problem' (that is, the need for the transformation of higher education for which there is a broad consensus) has become conflated with acceptance of the state's 'solution' (that is, the need for a rigorous external quality assurance system). The following cause and effect relations are assumed in the post-apartheid higher education policy discourse: external quality assurance will lead to the improvement of higher education management capacity, which will provide the conditions for high quality provision, which in turn will produce large numbers of high quality (especially black) graduates, which will lead to national economic and social development (Luckett, 2006).

In fact, the HEQC's mandate is a difficult one, as it combines both the improvement and accountability purposes of quality assurance, which in the quality assurance literature, are widely understood to exist in tension or even contradiction (Vroeijenstijn, 1995; Harvey \& Knight, 1996; Barnett, 1999). In addition, higher education institutions in South Africa are extremely diverse with large discrepancies in standards (Department of Education, 1997).[1] Furthermore, in 2003-04, when the empirical study for this paper was conducted, the 
HEQC, like any other regulatory agency, needed to win acceptance and legitimacy and to build sufficient consensus around its authority and policies in the higher education community, in order to get its policies and regulations implemented and institutionalised.

In 2004, the HEQC published four policy documents: Framework for institutional audit, Framework for programme accreditation, Criteria for institutional audits and Criteria for programme accreditation. Together these form the basis of the HEQC's complex 'integrated' quality assurance system. Implementation has been phased in giving time for pilot audits and for merged institutions to stabilise. National programme reviews were implemented from 2003, the accreditation of all new programmes from 2004 (the re-accreditation of existing programmes remains a provider function) and institutional audits were conducted from 2006. Details of the next phase of implementation from 2010, in which applications for self-accreditation status will be considered, are still awaited.

\section{A conceptual framework for analysing approaches to quality assurance}

Given that the idea of quality involves issues of power and values and that the introduction of a national quality assurance system is likely to be embroiled in efforts to empower new interests and challenge traditional values (Barnett, 2003; Morley, 2003), it would seem that an attempt to set up a conceptual framework for analysing quality assurance systems should focus not so much on how quality gets defined formally, as was on the agenda in the early 1990s, but rather on whose interests the quality assurance system serves; that is, the politics of quality is fore-grounded. The framework should be able to capture the answers to the following sorts of questions: 'Who decides what counts as quality?' 'Who decides what the criteria or measures of quality should be?' 'Who owns the quality system?' 'For whom is the evaluation done?' To capture the different possible answers to these questions, and drawing on the work of Barnett (1999) Brennan and Shah (2000), Harvey and Knight (1996) and Trow (1999), a modification of Barnett (1999) and Trow's (1999) frameworks is proposed. Trow proposed a framework for academic review (programme level) whilst Barnett proposed one that he claimed can be used for analysing quality systems at either institutional or national level. The framework proposed here was applied to stakeholder views on proposals for a national quality assurance system at programme, institutional and national levels gathered during an empirical project conducted during 2003-04 (Luckett, 2006). Barnett (1999) cautions that the grid has only general analytic value and that it cannot replace in-depth case studies of particular quality assurance systems, which will not always fall neatly into any one of the quadrants.

The horizontal axis labelled 'power and control' plots the power relations embedded in the quality assurance system. It distinguishes between quality assurance systems that are owned and controlled by actors internal to the academic community and those that are owned and controlled by external agents. Barnett (1999) pointed out that the issue is not 'who conducts the evaluation?', as academic peers are often used as evaluators by outside agencies, but rather 'to whom are they accountable and in whose interests are they acting?' Barnett emphasised that with respect to the 'power and control' axis, no value judgments about the virtues of either internal or external control are intended, as both modes exhibit strengths and weaknesses for quality assurance.

Regarding the vertical axis labelled 'purpose', Barnett (1999) suggested that it is normative in character, as a value judgment is implied. This axis plots the purpose of the quality assurance system, 'who is to be enlightened by the evaluation?' and, crucially, 'who determines the evaluation criteria?' Barnett suggested that this axis captures the answer to the 


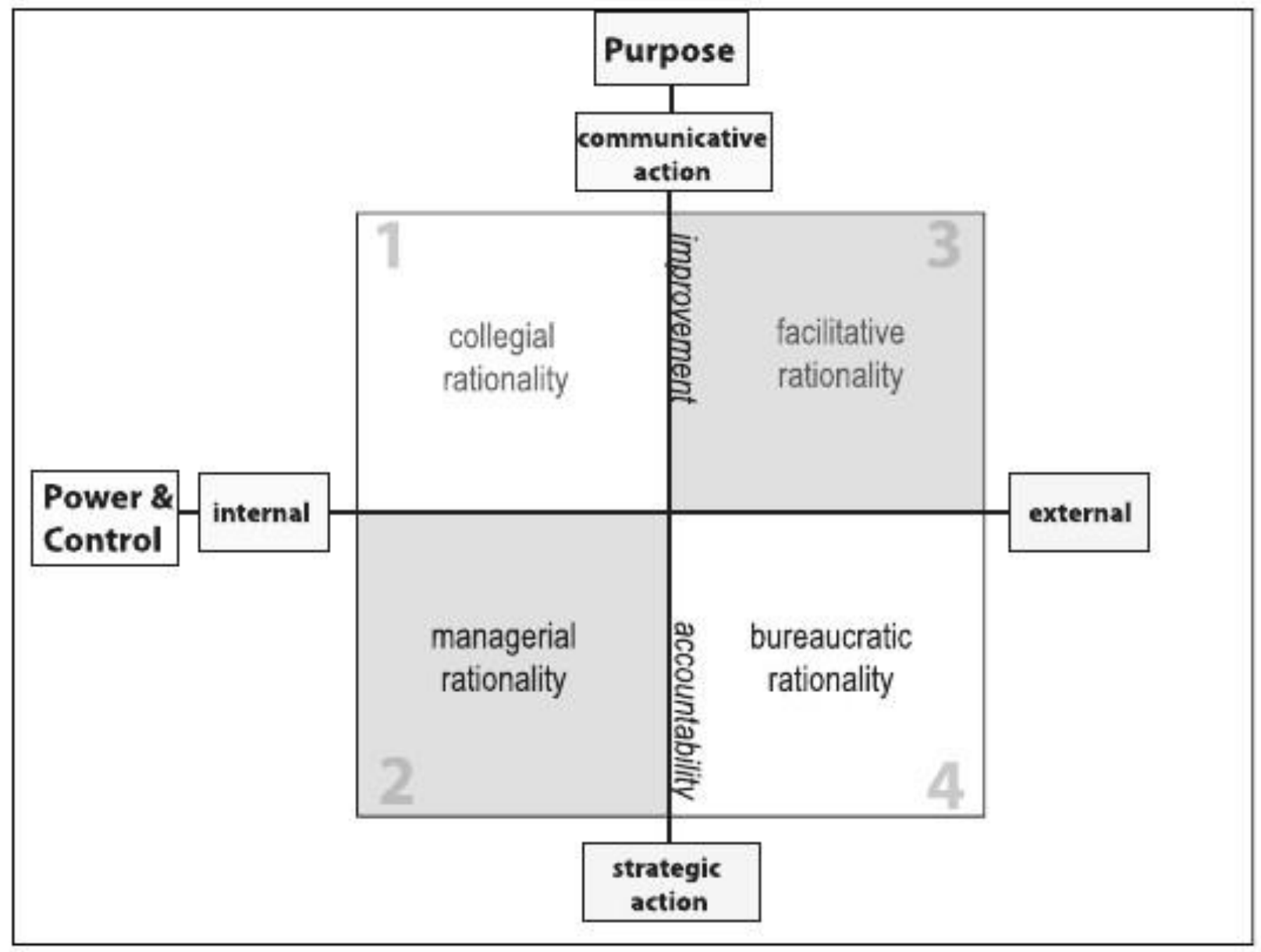

FIGURE 1. A conceptual framework for analysing approaches to quality assurance

question 'to what extent is the self-understanding of those being evaluated enhanced as a result of the evaluation process?' He noted that the vertical axis is based on an embedded premise, namely that self-understanding is maximised when it is self-generated and minimised when other-generated. His assumption was that improvement or change are most likely to occur through the advancement or transformation of self-understanding (Barnett, 1999). His implication was that the extent to which the evaluation has 'hermeneutic or dialogic value' the greater will be its capacity to generate self-understanding and improvement amongst academics.

Quality evaluation gains its greatest justification when, as a result, the actors centrally involved in offering programmes in higher education learn about themselves and, as a result, change, improve and even transform the quality of their own professional activities and services to society. (Barnett, 1999, p. 87)

Following Habermas (1987), one pole of the vertical axis has been labelled 'communicative action'. This refers to social action orientated towards mutual understanding in which participants are treated as genuine persons (as subjects rather than objects). The concept is linked to Habermas's 'theory of communication' in which he proposes a set of conditions and ethics for communication, which, if upheld, constitute a (utopian) 'ideal speech situation' undistorted by power relations, which Habermas maintains is the means to pursuing justice in a deliberative democracy. 
The second pole on the 'purpose' axis is labelled 'strategic action'[2] to convey the instrumental character of evaluation that is carried out to further the purposes of an authority or third party (usually state agencies or professional bodies); these purposes lie outside of the teaching and learning process.

In Habermas' early work $(1984,1987)$ on the theory of communication and discourse ethics, he understands strategic action as entirely negative; that is, as seeking its own ends and manipulating others in the process. But in his later work (1996), in which he develops a discourse theory of law, he uses strategic action to mean the 'procedurally regulated bargaining' that is necessary in democratic will-formation in order to take into account the concerns of different interest groups. The use here of the term 'strategic action' implies this later usage, in other words, certain forms of quality assurance have evolved to take into account the concerns and interests of a wide range of stakeholders such as governments, management and professions as well as students and academics. These different groups have valid but competing interests in higher education and they are not necessarily committed to communicative action to achieve them.

Barnett contends that the evaluation of teaching and learning conducted to serve the purposes of third parties is usually for accountability and is therefore unlikely to further the self-understanding of those engaged in the educational process itself. The framework places 'accountability' as the most likely purpose of evaluation at the strategic pole of the purpose axis and 'improvement' as the most likely purpose of evaluation at the communicative pole.

The framework gives four quadrants that were used to establish four caricatures of approaches to quality assurance. These four types were used in the empirical study to categorise interview material gathered from different groups of stakeholders. The quadrants are labelled as follows:

1. Collegial rationality.

2. Managerial rationality.

3. Facilitative rationality.

4. Bureaucratic rationality.

Quality assurance in Quadrant 3 tends to give external support and validation to evaluation that is based internally in Quadrant 1, whilst evaluation carried out in Quadrant 2 tends to be internally managed to meet quality assurance requirements that are based externally in Quadrant 4. Thus the 'inherent contradiction' in quality assurance practice identified by Barnett (1999), Harvey and Knight (1996) and Vroeijenstijn (1995) really lies between Quadrants 1 and 4. This contradiction becomes more explicit when articulated in the perspectives of different stakeholders in the policy process.

In Quadrant 1, an approach to quality assurance in higher education based on a collegial rationality is typically concerned with the production of knowledge (research) and the promotion of the disciplines, basing its norms and values on the idea of a 'community of scholars' and the liberal concept of 'academic freedom'. It defines quality as academic excellence and so tends to adopt a deficit view of students as novices or apprentices. A collegial approach to quality assurance is based on peer review; it uses a 'connoisseurial' and interpretive method of evaluation based on academic judgment by peers with appropriate disciplinary and experiential expertise. The criteria for quality usually remain implicit with judgments reached within the shared meanings of a disciplinary community. The consequences of the evaluation are usually non-threatening and do not involve extrinsic rewards or punishments. Criticisms of this approach are that it remains captured by the 'academic 
guild' (Trow, 1999) and tends to emphasise disciplinary excellence as opposed to good teaching of the discipline. Furthermore, connoisseurial evaluation is based largely on interpersonal transactions meaning that power and personality issues are often implicated in the judgments made. This means that the process often remains opaque to outsiders, in particular, to external stakeholders of higher education.

The approach to quality assurance based on a managerial rationality in Quadrant 2 works for the good of the higher education institution as organisation (Kogan, 2002; Barnett, 2003). Good management exercised through central control is seen as the solution to achieving organisational effectiveness and efficiency. Quality is typically understood as 'fitness for purpose' with students being viewed as clients or customers. The evaluation method adopted is typically 'pragmatic', that is, useful to decision-makers. The criteria for evaluation are institutional; that is, management's goals and objectives against which institutional performance is measured. The pragmatic method typically assumes that human achievement of pre-determined goals can be objectively measured and that measurement, sanctions and rewards will motivate improvements in performance. The consequences of pragmatic evaluation are often linked to internal decision-making and the allocation of resources (Brennan \& Shah, 2000).

The approach to quality assurance in Quadrant 3 is based on a facilitative rationality working from outside the disciplines or institution to support higher education managers and academics in their efforts to monitor and improve their performance. This approach tends to be adopted by agents of staff development (within and without the institution). It has a supportive but limited agenda and believes in the principle of self-regulation and the capacity of higher education to professionalise and account for itself. It tends to support the 'pedagogic project' that views students as co-participants in learning and subscribes to a view of quality as cognitive development and learner transformation (Harvey \& Knight, 1996). It tends to adopt a constructivist method of formative evaluation in which the evaluation criteria are generated internally by the evaluees. A criticism of this approach is that it naively assumes that the will and the capacity for self-development is universal, whereas this approach is difficult to sustain without structured support, resources and incentives. It may also be naïve about the effects of power and the way in which unequal power relations distort genuine attempts to be honest and to improve (Webb, 1996).

The approach to quality assurance in Quadrant 4, based on a bureaucratic rationality, believes in strong government or an 'evaluative state' (Neave, 1998) as a means of solving social problems. It works to promote the system-building interests (the state, the funder or the professional body) and the purpose of quality assurance is usually accountability and control. It subscribes to an understanding of quality as 'fitness of purpose' usually linked to that of 'value for money' and/ or 'fitness for purpose' [3] and tends to view students as clients, citizens or (potential) voters. As in the case of the managerial approach, it typically uses a goal-based, positivist and pragmatic method of evaluation; but involves external summative evaluation in which the criteria are based on the state or funder's purposes and goals for higher education. This means that standardised criteria are used to measure performance and accountability across a system with a focus on inputs, outputs and outcomes. If the approach uses internal evaluation first, the threat of subsequent external judgment tends to force the former into a defensive mode, thus limiting its potential for improvement (Trow, 1999). Peer review is often used as a means of conducting external evaluations but it is usually based on the use of standardised criteria, with an emphasis on 'neutral' and 'objective' judgment, thus limiting the scope for professional judgment. The 
outcomes of this approach are public judgments that have direct consequences for the evaluee's status, funding and reputation. Criticisms of this approach are that it applies the same treatment to all, assuming that one can validly and reliably use standardised criteria to measure performance across a system, regardless of differences in context. The focus on inputs, outputs and outcomes means that process is often ignored, leading to 'black-box' evaluations with limited diagnostic reach for improvement. The lack of easily quantifiable data to determine direct outcomes and impacts of messy social practices (such as education) sometimes lead to the acceptance of socially and politically correct data as valid for evaluation purposes. Perhaps the greatest weakness of this approach is that it struggles to deal with complexity and diversity meaning that its external criteria and judgments often appear arbitrary or meaningless to the evaluees, leading to either resistance or cynical compliance (Barnett, 1999; Morley, 2003).

\section{A case study to investigate stakeholder responses to the HEQC's policy proposals (2003-2004)}

The empirical research reported on in this paper took place during the period 2003-04 in the South African public higher education sector only,[4] when the HEQC was in the process of policy development and winning acceptance (policy adoption) for its policy proposals (HEQC, 2004a, b, c, d). In all, there were three rounds of data-gathering. In the first, the researcher was employed by the then South African Vice-Chancellors Association to gather and process institutional responses to the HEQC's draft policies on institutional audit and programme accreditation to inform a consolidated 'sectoral response' to the HEQC (SAUVCA, 2003). This research was conducted via structured self-administered questionnaires sent to every university in the country $(\mathrm{N}=21)$. The questionnaires were usually completed by quality assurance managers on behalf of their institutions. Institutional response rates to the questionnaires on the HEQC's audit and accreditation proposals were $60 \%$ and $71 \%$ respectively. The second round of data-gathering involved semi-structured interviews conducted with participants in workshops that the HEQC held around the country late in 2003 to introduce its new proposals and promote the improvement of teaching and learning. Interviewees were divided into three groups: senior academic managers (seven), quality assurance managers (nine) and academics (three). A fourth group, HEQC officials (six) were interviewed either at the workshops or at the HEQC head office in Pretoria. Third, a group of academics (eight) from three different institutional types who had been involved in preparing self-review portfolios or were interviewed during the site-visits for the HEQC's first round of national reviews (the MBA review of 2003-04) was interviewed, in order to gather a post-implementation sample of academics' views. Whilst the sample of South African universities that responded to the questionnaires provided coverage of the total population of universities, the sampling of interview respondents was both purposive and opportunistic; it was based on access to data that was naturally available to the researcher.

Individual stakeholders were also categorised as members of three institutional types that have existed historically in the South African system, but have recently begun to unravel in the process of enforced institutional mergers. These institutional types were characterised as:

- Historically English-medium institutions: these institutions had strong research cultures, liberal, collegial cultures and a history of opposition to the apartheid state. 
- Historically Afrikaans-medium institutions: these institutions had managerial cultures and a shared a history of compliance with the apartheid state.

- Historically black institutions: these institutions had a reputation of being weak and poorly managed with a history of student protest and state control and repression.

Qualitative data from these different sets of respondents (representing three institutional types and four different roles in the policy-making process) were coded into the four approaches to quality assurance set out in the conceptual framework to see what patterns emerged. The data were categorised and analysed at two levels. First, the data were interpreted as realist accounts and as sources of information; that is, it was assumed that respondents provided reasonably accurate information, for example, on the feasibility of the different policy instruments or about conditions surrounding the implementability of the HEQC's policies. Second, the same data were interpreted by the researcher as realisations of discursive practice, that is, as sources for interpretation that gave insights into the worldviews, values, discursive repertoires and 'orders of discourse' that the respondents drew upon when judging the HEQC's policies and the likelihood of these achieving their goals (see Appendix for set of interview questions). At this second level, the researcher looked for patterns of social meaning encoded in the discourses that were adopted by different sets of stakeholders. Discourse analysis was used to identify patterns in the respondents' texts that could be related to the four approaches to quality assurance set out in the conceptual framework. NVivo was used to code the texts accordingly.

\section{An analysis of stakeholder responses}

Regardless of their different understandings of the meaning of quality, all stakeholders agreed on the need for the external quality assurance of South African higher education. Unsurprisingly, given that the majority of respondents had some degree of vested interest in quality systems, there was widespread acceptance of the assumption that external quality assurance would result in improved quality management systems, which in turn would lead to improved provision. However, the clearest pattern that emerged from the data was linked to the type of institution where respondents worked, rather than to their role within those institutions. Without exception, those respondents who work in historically Englishmedium universities supported collegial or facilitative approaches to quality assurance, regardless of their 'social role'. On the other hand, the majority of respondents from historically Afrikaans-medium and historically black institutions supported managerial or bureaucratic approaches, but for different reasons. A generalisation that emerged from the data is that opposition to the HEQC's proposals came primarily from members of the historically English-medium liberal universities who claim to have collegial cultures and who viewed the proposals as a threat to academic freedom and institutional autonomy. Likewise, support for the HEQC's proposals came from three groups of stakeholders: those from well-managed institutions with functioning quality assurance systems and with compliance cultures (historically Afrikaans-medium institutions); those from reputedly weak institutions who hoped that an interventionist state would enforce improvements; and those who supported the government's vision for the transformation of the higher education system (these last two groups over-lapped and were mostly from historically black institutions).

This finding is supported by Hall et al.'s (2002) analysis of the changing nature of the state-higher education relationship in South Africa. Their analysis suggests that it is 
particularly those institutions that enjoyed a surprising degree of institutional autonomy and academic freedom during the apartheid era and that have a tradition and culture of state opposition and critical engagement (namely, the historically liberal English-medium universities), that are likely under the current government to express concerns about encroachments on institutional autonomy by the state. Whilst those institutions that historically never enjoyed such privileges, or historically had a culture of compliance, are more likely to accept state control as legitimate. This insight was expressed in an interview with a quality assurance manager from a historically Afrikaans-medium university.

You know the old story of the English-speaking universities in the old system they didn't listen to the government and they still don't. And in the old system the Afrikaans people listened very carefully to the Apartheid government and did everything expected from them and they still do so in the new system. So there is a cultural expectation that we will do these things at this university. ... So I think it's part of this kind of institutional culture that we will do it, we're going to hate it, but we'll do it. (QAM 5)

The analysis of the data showed that respondents' institutional contexts (invariably linked to their position in South African society's class-race structure) was the most consistent independent variable shaping respondents' approaches to quality assurance. If one accepts that the adoption and implementation of quality assurance policy must engage with agents' lifeworlds (see discussion below), then this can be explained by arguing that respondents' social position and institutional culture (in an historically divided society such as South Africa) was a stronger factor in determining their response to policy than their job description or their role in the policy-making and implementing process.

However, Muller (2003) points out that one cannot simply read off policy responses from institutional cultures and histories; one also needs to look at institutions' 'adaptive capacity'. Muller argues that those with strong adaptive capacities may choose to adapt to new policies (this seems to be the case for the historically Afrikaans-medium institutions) or alternatively they may resist or subvert changes that are not in keeping with internal norms and values (this may be the case for the historically English-medium institutions). According to Muller, those with weak adaptive capacity may give ideological support to new policies, but may lack the capacity to change themselves (this may be the case for some historically black institutions, unless the mergers and the HEQC's capacity development work enhances their adaptive capacities).

The following uses examples from the data to illustrate the analysis. Most of the academics interviewed expressed opinions based on a collegial rationality, (with some exceptions from those who work in black or Afrikaans-medium institutions). This academic from a historically English-medium university took an extreme liberal ideological position, which can be located in Quadrant 1, collegial rationality:

At the foundation of my dismay is the realisation that the type of discourse in the HEQC has become endemic in South African education at the national level and is steadily insinuating itself into every facet of higher education as well. It is a discourse of centrally controlled management (based on dated and increasingly obsolete ideas borrowed from the real business world that is steadily abandoning them, mixed up with a lot of Soviet era planned economy stuff that some of our exiles learned but did not abandon when the actual centrally-planned economies went down the tube.) 
It has one fixed idea-'control'. It is a discourse that has not the slightest real interest in any idea of the university in relation to thought and knowledge. It is the discourse of managers and of education as a (state-controlled) business. (A 3)

By way of contrast this young Afrikaans-speaking academic supported a managerial approach (Quadrant 2):

I agree that academics should be accountable, responsive and strive for good practice. Academic freedom without academic responsibility has no meaning. Academics need to question their freedom in relation to responsibility and accountability. ... So I support that the system should make us accountable. Of course, many academics are anti-managerialism and government control. But, as a researcher, I'm not convinced about the alternatives to a managerial approach. We need good transparent management and clear structures and reporting. I'm not clear on exactly what collegialism means for modern universities, what are its structural implications? Chaos and conflict? Our issues are complex and I don't think collegialism can deal with them. It is usually too informal and just creates conflict. If collegiality means having a good discussion on what has worked and what hasn't worked within an internal QA system as I described earlier, this makes sense to me. For me, the managerial approach brings clarity and structure; I can't see how this can be bad, given our scale of operation and the levels of complexity. Maybe l'm just a pragmatist, but I remain unconvinced that arguments about academic freedom, autonomy and collegiality can provide real alternatives for running an HEI. I don't think it's any longer an alternative just to do your own thing. (A 1)

This quality assurance manager from a historically English-medium university expressed a commitment to the facilitative approach (Quadrant 3) and wanted the HEQC to do the same:

We are going to set up an internal system that we think will work based on an understanding of quality that we believe in and hope that at some point these will meet the HEQC's demands. Their ad hoc demands will result in minimum compliance. We won't use their policy documents as points of departure, we want to develop our own systems, but make sure that they are not entirely different-obviously we don't want to make academics do double work. Our thrust will be internal, much more developmental and friendly (what we originally wanted and hoped the HEQC would be). You know, we wanted them to be a national body that had expertise and could help develop our systems, finding holes in our internal systems and sending consultants to help us. We wanted them to add value and to give us guidelines-a resource rather than a policing body. But the HEQC is forcing us into a policing mode. ... No paperwork will fix a bad teacher. It is the teacher-student relationship which is the key to quality, if you can't fix this at the coal-face then you can't fix quality. We will try to get communities of people talking to each other, we will encourage self-reflection, identifying quality gaps and finding solutions together. At both group and individual level we want open and honest discussion. At this institution our assumption is that everything works (more-or-less) although the merger might change that. Our programmes and modules exist and we will not use quality as a feasibility exercise or to restructure or close down programmes. We are working rather to get the academics to improve them themselves. (QAM 1) 
By way of contrast, this quality assurance manager from a historically Afrikaans-medium university expressed a position more sympathetic to the HEQC, that could be classified as a weak managerial position (Quadrant 2):

The balancing of accountability and improvement is always a problem in QA systems. There has been a shift towards accountability by the HEQC since the Founding Document of 2001... I think they will achieve their purpose with respect to accountability. But the question is what kind of accountability? They may achieve a superficial compliance kind of accountability, but not an authentic accountability that is owned by academics and departments. Academics don't generally yet embrace the idea that they should be accountable as a legitimate requirement, they see it as an external imposition. On the one hand I can understand why the HEQC went the way that it did, for example, the production of criteria and taking the initiative away from HEls. But the imposition of criteria by a national QA body will inevitably result in a compliance culture. We had hoped for a more developmental path where academics could be asked to determine internally what criteria are applicable to them. On the other hand one could ask 'What's wrong with compliance?' At our stage of national development we do need certain minimum thresholds, and there should be no uncertainty about what should be in place to ensure acceptable standards in certain institutions. I do understand the argument that we need clarity and consistency. But the danger is in the way the criteria are communicated and implemented in practice. Will HEls be encouraged to make the criteria their own and adapt them to their contexts or will they be rigidly imposed from without? (QAM 2)

The power of institutional context and in shaping the responses to HEQC policy proposals was illustrated by this quality assurance manager who had worked in both a historically black and a historically English-medium institution:

I mean if I think back to X, they didn't need a stick they needed a bomb! You get some institutions where people are selling mark changes on the computer system and issuing fake degrees. If you've got that level of academic corruption and if you've got people who don't bother to go to their lectures, if you've got people, like I witnessed, who pick up a script from an enormous pile and says this sounds like a 67 to me and puts 67 on the paper without opening the script. There were practices that I witnessed that need a tough régime to go in and say 'this cannot continue'. But the trouble is then you've got other more thoughtful places which aren't all good but still have an integrity about them and you've got to be careful that you don't destroy that integrity and that thoughtfulness. ... So implementing a rational QA system is an impossible task because of the disparity and diversity in the system. But then politically can you have anything other than a one-size-fits-all approach? (QAM 6)

The senior academic managers interviewed were divided between taking facilitative or managerial positions. Those from historically English-medium universities took facilitative positions (Quadrant 3), whilst all but one respondent from Afrikaans-medium or historically black institutions took managerial positions (Quadrant 2). This senior manager from an English-medium university manager demonstrated an understanding of limits of managerialism and a desire to protect the traditional collegial practice of expert peer review. 
Conceptually we need to keep quality and quality assurance separate, achieving quality should not be confused with having a QA system. QA and accountability is necessary, but is not directly an improvement device. Setting up a good QMS will not necessarily lead to a good quality education system. This is where the HEQC is making a wrong assumption. QA is a management tool, let managers manage and use QA to manage well. But quality is what the academics should be concerned about, let them demonstrate this to each other-no one else can judge quality ...

Instead the HEQC is going for a heavily over-prescriptive approach, which removes opportunities for innovation and feeding self-involvement. Instead of saying ' $\mathrm{Hmm}$, this is an interesting challenge', academics will be saying 'What can I do to get this off my back?' (AM 3)

By way of contrast, the following programme manager from a historically black university supported a managerial approach, welcoming the HEQC's intervention as a means of forcing greater accountability on the part of academics.

Well, I think it just makes them [academics] accountable for what they do. They're not here to just sort of sit here and dream, you know, they're here to teach, to develop and to research. And they have to account for the time they're spending. And I think it's a good thing. It's a very, very free work environment and yet it requires a lot of self-discipline and it can actually go very awry if you're not delivering. (MBA 7)

This position was supported by several respondents from historically-black institutions who supported the HEQC's proposals in the belief that they would effect improvements in their institutions, 'It is in the interests of students to have an effective QMS in place'; 'We welcome the HEQC's efforts well done, but please do not punish us, rather develop us'; 'It will be a wake-up call for some-they may see it as a means of improvement'; 'Some will be pleased to have guidelines, they will appreciate that the criteria are academically valid' (comments at HEQC workshops, field-notes). Others from historically-black institutions supported the proposals for ideological reasons; they were supportive of the government's transformation agenda, 'We need these changes to ensure that imbalances and injustices are addressed'; 'Remember the history of South African education, we need radical transformation to ensure the provision of good education for the majority of students, who are black'; 'There is no need for institutional missions to be out of step with the transformational agenda'; 'The DoE's national plan should be implemented' (comments at HEQC workshops, field-notes).

The data presented here illustrates how those adopting collegial or facilitative approaches tended to oppose the imposition of the HEQC's policies, whilst those adopting managerial or bureaucratic approaches viewed them much more favourably. The analysis showed that these patterns were more strongly related to respondents' institutional cultures and contexts than to the roles that they played in the policy-making and implementation process. This suggests that the diversity of the South African higher education system is one of the key challenges facing the successful implementation of a 'one-size-fits-all' national quality assurance system.

Some of the HEQC officials interviewed expressed views typical of the bureaucratic approach (Quadrant 4), but the more senior officials tended to express more nuanced 
facilitative positions (Quadrant 3). The following official asserted that the HEQC's proposals were deliberately designed to meet the needs of the South African context and that once transformation and inequality (policy goals) had been achieved through accountability measures, the HEQC would be in a position to withdraw.

There is no trade-off between equity and quality-this is only in the minds of academics and QA managers. I know that the pragmatic QA in HE literature says that there is always a trade-off between accountability and improvement. This may be true in developed countries such as Holland, where there is a well-established system without huge social disparities. Here QA just keeps the system on a continuous improvement trajectory. So don't underestimate the nature of society and how it differs with the First World. We need to understand the context of quality and the meaning of 'fitness of purpose' for our context and once this is established, then design instruments to measure 'fitness for purpose'. So we first need to deal with transformation and inequality and from there move the system towards selfregulation. So we will start off with a system that needs strong external evaluation as an important tool for measuring and getting minimum standards in place. We need a QA system that emphasises the duality of accountability and development and their inter-relatedness. We will do development work, but people must first do self-evaluations repeatedly, leading to a culture of self-assessment and ultimately towards self-accreditation. We will measure everyone with the same yardstick from zero-based assumptions. We will build a legitimate system based on the same criteria, and then later leave it to run itself. (HEQC 3)

In contrast, this HEQC official expressed a view typical of the facilitative approach:

How do we make sure that we get the benefits of quality assurance and not the worst horrors and nightmares of quality assurance? You know we must avoid bureaucratisation, and the compliance approach ... And then I think the issue of acceptance is very important because I don't think you can just instruct people, just as I don't believe you can just legislate quality from the HEQC in Pretoria. You know similarly HE management can't just legislate improvements in teaching learning practice. So we have to provide incentives, good teaching awards and those kinds of things ... But I think certainly it's getting the balance right between the carrot and the stick but I think much more carrot in relation to teaching and learning-you know I don't know how one does that in an environment where everyone is tired. How do you get tired people excited about teaching? (HEQC 2)

The following senior official explained that the HEQC supported both the improvement and the accountability poles in the debate over approaches to quality assurance and saw the self-regulation of institutions as its long-term goal. He also indicated that he viewed higher education as a means of furthering national development. He went on to make the important point that if the HEQC emphasises one position at a particular moment (in this case accountability) this is a strategic rather than a principled decision. He also admitted that some of his juniors might be over-zealous about intervention.

Both fitness of and fitness for purpose are important for us. National goals should frame institutional missions, following Castells, we see HE to be the motor of 
national development. ... In the enterprise of creating a national QA system we have to keep both poles in balance. If one or other is fore-grounded at a particular time, that is a strategic decision, rather than one of principle. Contestation around these tensions is healthy. We need to hold the balance over time and take a long view-it will shift with different actors giving different emphases and readings. ... Centralised intervention is only a last resort-it is not our aim-rather our goal is self-regulation. I can understand that in practice an HEQC official may err on the side of intervention, we also need to get the right balance within the organisation. (HEQC 1)

The data analysis of the texts of HEQC officials suggested that, whilst some of the more senior officials saw the facilitiative (Quadrant 3) position as their final goal, the need to ensure transformation was initially pushing them towards a more bureaucratic approach (Quadrant 4).

The problematic of system and lifeworld in quality assurance

The tension between accountability (achieved via strategic action; treating people as objects) and improvement (achieved via communicative action; treating people as subjects) in a quality assurance system is often viewed as a simple either/or matter. However, some quality assurance literature and insights from Habermas' work suggest that this is an unhelpful dichotomy.

Habermas $(1984,1987)$ gives an account of modernity in which, because of increasing pluralism and 'disenchantment', the background consensus required for communicative action has diminished. This means that traditional practices (for example teaching in a university) have to be rationalised (abstracted and generalised) in order to bring them into the public sphere, where, increasingly, expert systems emerge around truth claims via rational argumentation (for example law, education and art). In modern societies communicative action emphasises abstracted principles and procedures over specific contexts and contents, thus creating new discourses around social practices (Chouliaraki \& Fairclough, 1999). Following Weber, Habermas regards these communicative value systems as 'sacred' whilst those dealing with the economy and the state he regards as 'profane'. In modern societies 'sacred' lifeworld systems based on communicative action become separated from 'profane' systems based on instrumental action. Instrumental (or strategic) rationality 'steers' by using the medium of money or power to get results, whilst communicative action works through rational argumentation to create meaning and understanding (enlightenment). But it is crucial to understand that Habermas does not understand these two forms of action or social practice as existing in a mutually exclusive relationship but, rather, as mutually constitutive; he argues that modern societies require a measure of both forms of rationality.[6] Importantly for quality assurance, Habermas understands instrumental systems to function productively only when they are accepted, institutionalised and anchored in people's lifeworlds. He warns of the danger of allowing instrumental systems to 'colonise' lifeworld systems through bureaucratisation (by the state) or commodification (by the market). Chouliaraki and Fairclough explain Habermas's political project:

The political project is not replacing instrumental by communicative rationality, it is (negatively) preventing instrumental rationality from spreading too far at the 
expense of communicative rationality with socially pathological consequences, and (positively) creating the social conditions in which the fully emancipatory potential of communicative rationality can be realised. (Chouliaraki \& Fairclough, 1999, p. 84)

Habermas (1996) builds on this theory of the relationship between 'lifeworld' and 'systems' in his later work on the law. He argues that the law should be 'Janus-faced' consisting of 'facts' enforced through the medium of bureaucratic power (instrumental action) and 'norms' agreed to through rational dialogue (communicative action). He argues that in a 'deliberative democracy' the law should work primarily through consent to norms with the enforcement of facts used only as a last resort when communicative action breaks down.

Habermas's theorisation of the law provides support for those who argue that if quality assurance is to result in the enlightenment of the evaluees it must be primarily based on communicative action that is anchored in the lifeworlds of the academic community (Harvey \& Knight, 1996; Barnett, 1999; Trow, 1999). Improvement is understood as a function of agency rather than structure and thus arises from the intrinsic motivations and of its agents. In other words, improvement must make sense from within the understandings and lifeworlds of those who must carry it out. Policy and regulations (and in this case an external quality assurance system) that work at the level of structure can lay the conditions for improvement, but cannot of themselves effect improvement (they can only enforce compliance). This position allows both the improvement and accountability motivations to exist in a quality assurance system, but to be effective and to lead to sustained improvement, it would argue that communicative action should dominate. In other words, a quality assurance system should be designed to ensure that instrumental action (necessary accountability requirements) enforced by the bureaucratic power of the state does not unduly colonise the lifeworld systems of academic institutions. If this happens the system will not 'make sense' to those who must use it and they will either cynically comply or subvert its intentions (see Harvey's 'compliance axis', 1999).

This discussion throws light on the vexed issue of accountability versus 'academic freedom' in higher education. The following compromise is suggested: 'academic freedom' and academic discretion should be upheld, not as rights but as conditions for scholarship and as a social contract that should work for the public good rather than as a licence to serve selfinterest or disciplinary interests alone. At the same time, accountability for the expenditure of public money should be recognised as a basic democratic principle that, in a new democracy such as South Africa, should be asserted and upheld. However, wise governments should ensure that accountability requirements do not compromise or in any way undermine the proper discharge of the public service itself (Bowden \& Marton, 1998). In addition, in ensuring accountability, government bureaucrats should not exceed their competence by aspiring to make academic judgments.

Habermas would view conflict and contestation as unavoidable in modern pluralistic societies - and, one might add, inevitable in a deeply divided society such as South Africa. But his (somewhat utopian) project was to provide a means of containing disagreement within a rational and dialogical form of communication. Indeed, this is the challenge facing senior managers in South Africa's universities and in the HEQC, namely to ensure that, in the process of implementing a national system of quality assurance in South Africa, contestation between those adopting collegial and bureaucratic approaches to quality assurance is contained within rational and dialogical communication. 


\section{Notes}

1. Since the empirical work for this study was conducted these discrepancies and the clear definition of institutional types have to some extent been off-set by the institutional mergers.

2. In everyday usage the term instrumental would better capture my intended meaning. But

Habermas reserves the term 'instrumental action' specifically for utilitarian action towards non-human phenomena as distinct from 'strategic action' which refers specifically to utilitarian action towards other people.

3. 'Fitness of purpose' cannot stand on its own as an adequate definition of quality; it needs to be linked to a check on implementation and outcomes, e.g., to 'fitness for purpose', in order to ascertain the extent to which the 'fit' purposes of higher education are in fact being achieved. In other words, there is little point setting politically correct goals for an institution without also checking whether the institution is attaining these (Lee Harvey, personal communication).

4. There is a growing private HE sector in South Africa that also falls under the HEQC's jurisdiction.

\section{References}

BARNETT, R., 1999, 'Power, enlightenment and quality evaluation', in CHEPS (Ed.) Quality management in higher education institutions (pp. 73-88) (Utrecht, LEMMA).

BARNETT, R., 2003, Beyond all reason: living with ideology in the university (Buckingham, The Society for Research into Higher Education).

BOWDEN, J. \& MARTON, F., 1998, The university of learning: beyond quality and competence in higher education (London, Kogan Page).

BRENNAN, J. \& SHAH, T., 2000, Managing quality in higher education: an international perspective on institutional assessment and change (Buckingham, The Society for Research into Higher Education).

CHOULIARAKI, L. \& FAIRCLOUGH, N., 1999, Discourse in late modernity (Edinburgh, Edinburgh University Press).

DEPARTMENT OF EdUCATION (DoE), 1997, Education White Paper 3: a programme for the transformation of higher education (Pretoria, Government Gazette No. 18207).

DEPARTMENT OF EDUCATION (DoE), 2001, National plan for higher education (Pretoria, Department of Education).

HABERMAS, J., 1984, Theory of communicative action. Volume 1: reason and the rationalisation of society (Boston, MA, Beacon Press).

HABERMAS, J., 1987, Theory of communicative action. Volume 2: lifeworld and system: a critique of functionalist reason (Boston, MA, Beacon Press).

HABERMAS, J., 1996, Between facts and norms: contributions to a discourse theory of law and democracy (Cambridge, Polity Press).

Hall, M., Symes, A. \& ThieRRY, M. L., 2002, Governance in South African higher education (Pretoria, Council on Higher Education).

HARVEY, L., 1999, 'Evaluating the evaluators', paper presented at International Network of Quality Assurance Agencies in Higher Education, Santiago, Chile.

HARVEY, L. \& KNIGHT, P. T., 1996, Transforming higher education (Buckingham, The Society for Research into Higher Education).

HIGHeR EducATION QUALITY COMmiTTEe (HEQC), 2004a, Criteria for institutional audits (Pretoria, Council on Higher Education).

HIGHER EdUCATION QUALITY COMMITTEE (HEQC), 2004b, Criteria for programme accreditation (Pretoria, Council on Higher Education).

HIGHeR Education QualiTy COMmitTEe (HEQC), 2004c, Framework for institutional audits (Pretoria, Council on Higher Education).

HIGHER EdUCATION QUALITY COMMITTEE (HEQC), 2004d, Framework for programme accreditation (Pretoria, Council on Higher Education).

KOGAN, M., 2002, 'The role of different groups in policy-making and implementation: Institutional politics and policy-making' in TROWLER, P. R. (Ed.) Higher education and institutional change: intentions and outcomes in turbulent environments (Buckingham, The Society for Research into Higher Education).

LUCKETT, K., 2006, The quality assurance of teaching and learning in higher education in South Africa: an analysis of national policy development and stakeholder response. Unpublished dissertation, University of Stellenbosch.

MORLEY, L., 2003, Quality \& power in higher education (Maidenhead, The Society for Research into Higher Education). 
MULLER, J., 2003, 'Knowledge and the limits to institutional restructuring: the case of South African higher education', Journal of Education, 30, pp. 101-26.

NeAVE, G., 1998, 'The evaluative state reconsidered', European Journal of Education, Research, Development and Policies, 33(3), pp. 265-84.

RePUblic OF SoUth AfricA, 1997, Higher Education Act (No.101) (Pretoria, Government Printer).

SOUTH AFRICAN UNIVERSITIES VICE-CHANCELLORS' ASSOCIATION (SAUVCA), 2003a, Response to proposed criteria for the HEQC's first cycle of audits 2004-2009 (Pretoria, South African Universities Vice-Chancellors Association).

SOUTH AfRICAN UNIVERSITIES VICE-CHANCELLORS' AsSOCIATION (SAUVCA), 2003b, Response to the proposed criteria for the HEQC's programme accreditation cycle 2004-2009 (Pretoria, South African Universities ViceChancellors Association).

TAYLOR, S., RIZVI, F., LINGARD, B. \& HENRY, M., 1997, Educational policy and the politics of change (London, Routledge).

TROW, M., 1999, 'Academic reviews and the culture of excellence', in CHEPS (Ed.) Quality management in higher education institutions (pp. 9-34) (Utrecht, LEMMA).

VROEIJENSTIJN, A. I., 1995, Improvement and accountability: navigating between Scylla and Charybdis (London, Jessica Kingsley Publishers).

WEBB, G., 1996, Understanding staff development (Buckingham, Society for Research into Higher Education). 


\section{Appendix. Interview schedules used in the empirical study}

\section{Interview schedule for HEQC officials}

1. What has been the general response of the HE community to the Audit Criteria discussion document?

2. Are there any substantial changes that the HEQC is likely to make as a result of the responses?

3. What do you think are the key values that underpin the HEQC's work? To what extent do these values differ from those of typical academics?

4. Are you confident that the HEQC has sufficient resources and capacity at its disposal to run institutional audits and to accredit programmes across the system-as it is required to do by law?

5. Do you think that the HEQC's approach to linking audit and accreditation is going to work? What will it take?

6. What do you think are the key conditions for successful implementation of the HEQC's QA system?

7. What do you believe to be the mechanisms that will really effect change in everyday teaching and learning practice in HE institutions?

8. To what extent does the HEQC have control over these conditions and mechanisms?

9. What changes are needed in the system in order for the HEQC's QA system to operate effectively?

\section{Interview schedule for academic managers}

The macro-question is: 'To what extent you believe the HEQC's policy instruments (the two Framework Documents, the Proposed Criteria for Audit and Accreditation, the proposals for self-accreditation, the MBA Review, supported by the Improving Teaching \& Learning Resources) are valid, acceptable, feasible and potentially effective?'

1. Do you think that the policy instruments that the HEQC has produced so far are based on adequate expertise?

2. To what extent are the the HEQC's policy instruments implementable in your context/ institution?

3. What are the resource implications of implementation?

4. What are the constraints to successful implementation in your own institution? And to what extent can you overcome these?

5. How do you intend to mediate the HEQC's demands in the internal quality management system you are setting up for your institution?

6 . How do you think academics are going to respond to the implications for them of the HEQC's requirements?

7. What (if any) underlying paradigm/value/worldview clashes exist between the HEQC's conceptualisation and operationalisation of quality in $\mathrm{HE}$ and your own/and those of the academics in your institution?

8. To what extent do you think the HEQC's policy instruments will fulfil their purposenamely to ensure accountability and improve the quality of HE provision? In your own institution? Country-wide? 
9. Any other comments related to the national QA project and your management of quality at your institution?

Interview schedule for quality assurance managers

The macro-question is: 'To what extent you believe the HEQC's policy instruments (the two Framework Documents, the Proposed Criteria for Audit and Accreditation, the proposals for self-accreditation, the MBA Review, supported by the Improving Teaching \& Learning Resources) are valid, acceptable, feasible and potentially effective?'

1. Do you think that the policy instruments that the HEQC has produced so far are based on adequate expertise?

2. Who do you think should have been involved in the HEQC's policy development process?

3. To what extent are the the HEQC's policy instruments implementable in your context/ institution? What are the constraints to successful implementation?

4. How do you think academics are going to respond to the implications for them of the HEQC's requirements?

5. What (if any) underlying paradigm/value/worldview clashes exist between the HEQC's conceptualisation and operationalisation of quality in $\mathrm{HE}$ and your own/and those of the academics you work with?

6. How do you intend to mediate the HEQC's demands in the internal quality management system you are setting up for your institution?

7. To what extent do you think the HEQC's policy instruments will fulfil their purposenamely to ensure accountability and improve the quality of HE provision? In your own institution? Country-wide?

8. Any other comments related to the national QA project and your institutional QA work?

(If you are in a management position, please comment on resource implications.)

\section{Interview schedule for academics}

The macro-question is: 'To what extent do you think that the HEQC's policy instruments and processes are acceptable, legitimate, feasible and potentially effective?'

1. What is your position, in principle, with respect to being accountable to the government for the quality of the programmes you teach on? To what extent do you agree with the idea of an external quality assurance agency, established by the Department of Education, assuring and maintaining quality in the higher education system?

2. What was your experience of the HEQC's workshop?

3. What did you learn from it?

4. To what extent do you think that the HEQC's Improving Teaching \& Learning

Resources will be used and have an impact on teaching and learning at your institution?

5. Do you think that the HEQC's policy instruments and processes adequately take into account the interests and concerns of academics on the ground?

6. What are the consequences, costs and risks of the HEQC's policies for you and your academic work?

7. Do you have any recommendations for the HEQC in terms of winning legitimacy or 'buy-in' for its external quality assurance requirements from academics? 
8. What criteria would you set for yourself to measure improvement in your own teaching programmes? How do you think quality assurance should be carried out in order to effect improvements in teaching and learning?

9. In what ways, if any, do the values and assumptions that underpin the HEQC's policy instruments differ from your own with respect to the quality of higher education provision?

10. Any other comments?

\section{Interview schedule for MBA academics}

The macro-question is: 'To what extent do you think that the HEQC's policy instruments and processes are acceptable, legitimate, feasible and potentially effective?'

1. What was your involvement in the MBA re-accreditation process?

2. What is your position, in principle, with respect to being accountable to the government for the quality of the programmes you teach on? To what extent do you agree with the idea of an external quality assurance agency, established by the Department of Education, assuring and maintaining quality in the higher education system?

3. In practice, did you gain anything useful or valuable from the self-evaluation process undertaken in preparation for the HEQC's site-visit?

4. What was your experience of the HEQC's site-visit?

5. What did you learn from it?

6. Do you think that the HEQC's evaluation instrument and process adequately takes into account the interests and concerns of academics on the ground?

7. To what extent do you think that the HEQC's instrument for the re-accreditation of MBAs is realistic and feasible in terms of the demands it makes on academics?

8. What are the consequences, costs and risks of the HEQC's policies for you and your academic work?

9. To what extent do you think the HEQC's instrument and process will be effective in assuring the quality of MBAs around the country? And in improving the quality of teaching and learning on MBAs?

10. Do you have any recommendations for the HEQC in terms of improving the process? 11. How do you think quality assurance should be carried out in order to effect improvements in teaching and learning?

12. In what ways, if any, do the values and assumptions that underpin the HEQC's policy instruments differ from your own with respect to the quality of higher education provision?

13. Any other comments? 